\title{
ORAL HEALTH RELATED QUALITY OF LIFE AMONG A GROUP OF EGYPTIAN PRESCHOOL CHILDREN AFTER DENTAL TREATMENT UNDER GENERAL ANESTHESIA
}

\author{
Manal A. El Sayed*
}

\begin{abstract}
Objectives: This study was conducted to describe the impact of oral health problems resulting from Early Childhood Caries (ECC) on the quality of life of the child and his family, and the effect of dental treatment under General Anesthesia (DGA).

Study design: Children participated in this study were referred to General anesthesia Unit during July, August, and September 2015. All children were preschool with an age ranged between 2 to less than 6 years, suffering from $\mathrm{ECC}$ with minimum $\mathrm{dmf}=4$. The parents received a questionnaire called Early Childhood Oral Health Impact Scale (ECOHIS) on the day of the GA session to be completed about the child's oral health conditions and well-being over the past 3 months. Then the same questionnaire was used and completed once again at the first follow up visit one month later.

Results: The total ECOHIS and all ECOHIS domains were significantly and dramatically improved except for the domain of child psychology. The most reported items for the child after GA treatment was difficulty in eating (14.4\%) followed by pain $(9.4 \%)$. While for the family the most reported item was the financial burden $(7.2 \%)$.
\end{abstract}

Conclusions: ECC has a great impact on the quality of life of both children and their families High scores of ECOHIS were recorded before DGA which means poor quality of life, while these scores were dramatically decreased after DGA with a significant improvement in the quality of life.

KEY WORDS: Early Childhood Oral Health Impact Scale, Dental Treatment, General Anesthesia, Quality of life.

\section{INTRODUCTION}

The World Health Organization ${ }^{(1)}$ defines health in terms of physical, psychological and social well beings. Oral and dental health conditions are very important factors affecting the child's quality of life and have an impact on the child's growth, body weight, degree of socialization, self-esteem and learning abilities ${ }^{(2,3)}$.

\footnotetext{
* Associate Professor of Pediatric Dentistry Faculty of Dentistry, Cairo University
} 
Dental caries is the most chronic childhood non self-limiting oral disease. It can affect the child physically, emotionally and intellectually ${ }^{(4)}$.

Several studies proved that dental diseases including dental caries affect the child's development and wellbeing ${ }^{(5.6,7)}$.

Early childhood caries (ECC) is one of the most common dental health problems affecting infants, toddlers and preschool children ${ }^{(8)}$. It is a serious public health problem in both developing and developed countries with an aggressive pattern that begins at an early age, progress rapidly and has an immediate and long term effect on the quality of life of both the child and his family ${ }^{(9)}$.

Pain is usually a common complain among children suffering tooth decay and the child may have days absent from nursery or school either due to pain or due to an arrangement for a dental appointment. Additionally, a child with ECC may experience problems related to eating, sleeping pattern and school performance ${ }^{(4)}$.

Studies in the field of pediatric dentistry have focused on the prevalence and risk factors of ECC such as microbiological background, salivary characteristics and clinical features $(4,10,11)$ however few studies have been reported concerning the impact of ECC on the Oral Health Related Quality of Life (OHRQoL) in preschool children (12,13) although a high prevalence of dental caries has been recorded during childhood and described in the literature ${ }^{(11,14)}$.

ECC not only has a negative impact on the child but also on hisher family or care givers. They usually feel guilty towards the child in addition to some concerns about treatment costs, accessibility to dental care services as well as stresses related to the affected child. All these issues may affect the family's quality of life in terms of sleepless nights, time lost from work, travel or transportation expenses and financial burden in general ${ }^{(15)}$.
OHRQoL can be defined as the impact of oral health or disease on an individual's daily functions and life style ${ }^{(16)}$.

Although most of children with ECC are able to be treated in conventional dental sessions, still some fail to respond in a good manner to the psychological behavior management techniques and should be treated under General Anesthesia which became more accepted by the parents nowadays than earlier ${ }^{(17,18)}$. By evaluating the OHRQoL for the child and his family after dental rehabilitation under general anesthesia, several studies have shown a significant improvement regarding pain sensation, eating problems, sleeping pattern as well as the general health. Additionally the parents noticed and reported more social activity, improved school performance and increasing growth parameters ${ }^{(16,19,20,21)}$.

When measuring the impact of dental treatment, it is very important to assess not only the clinical changes but also the effect of that treatment on the quality of life. OHRQoL is measured in relation to how the teeth and oral structures affect all the child's activity and wellbeing as well as the family functions and happiness.

In order to evaluate OHRQoL a standardized method or questionnaire is needed. Some questionnaires are already available and used among children for this purpose ${ }^{(22,23,24,25)}$ and one of them was Early Childhood Oral Health Impact Scale (ECOHIS) which has been specifically designed and validated for preschool children in English speaking countries ${ }^{(24)}$. This valid questionnaire consists of 13 questions which 9 of them concerned about the impact of oral health on the child and 4 questions for the family regarding their daily activities.

Recent studies were conducted to evaluate the impact of dental treatment under GA on children's OHRQoL and reported a significant improvement in the oral health ,psychological ,social, and overall wellbeing of the child as well as a positive impact on the family $(26,27,28)$. 
To the best of our knowledge few studies have been conducted in Egypt regarding the quality of life and dental treatment under general anesthesia one of them was a Master thesis which was conducted in the faculty of Dentistry Alexandrea University 2014. Accordingly, this study was designed to evaluate and assess to what extent dental treatment of children under GA can change the oral health related quality of life of children and their families.

\section{AIM OF THE STUDY}

The aim of this work was to describe the impact of oral health problems resulting from ECC on the quality of life of the child and his family, as well as to evaluate and compare the effect of dental treatment under GA on the quality of life.

\section{SUBJECTS AND METHODS}

All children participated in this study were investigated, screened and referred to GA unit from the out patient's clinic of the Pediatric Dentistry Department , Faculty of Dentistry , Cairo University during July, August, and September 2015.

Both sexes were included and their parents were of different educational levels (high, middle and low). All children were preschool with an age ranged between $2 \leq 6$ years, suffering from ECC with minimum $\mathrm{dmf}=4$.

All of them were apparently healthy and any child with special needs or medically compromised was excluded from our study.

Before starting the work an approval was obtained from the ethical committee of the Faculty of Dentistry, Cairo University . As well as a signed written consent and approval from the parents of all participants was obtained before starting this work.

\section{Sample size:}

Sample size calculation was done using the comparison of total ECOHIS score between before and after dental surgery under GA among 2-6yes old children as it was the primary outcome of our study. As reported in previous publication (16), the mean \pm SD of pre-treatment total ECOHIS was approximately $21.3 \pm 6.9$, while it was $6.5 \pm 4.8$ after surgery. Accordingly, we calculated that the minimum proper sample size was 45 patients be able to detect a real difference of 3 unit with $80 \%$ power at $\alpha=0.05$ level using Paired t test. As we are planning to divide the sample into males and females as well as divide into 2 age groups, the final sample size will be 180 participants. Sample size calculation was done using Stats Direct statistical software version 2.7.2 for MS Windows, Stats Direct Ltd., Cheshire, UK.

For evaluation of the OHRQoL the parents of all participated children ( no.=180) received a questionnaire which was especially designed for preschool children in English speaking countries ${ }^{(26)}$. This questionnaire was called Early Childhood Oral Health Impact Scale (ECOHIS). It is parentassessed method to evaluate the impact of ECC and its consequences on preschool children and their families.

ECOHIS involved two sections one of them is for the child (four domains) and the other is for the family( two domains)

\section{Child's four domain:}

First domain: (one question about pain):

1. How often has your child had pain in the teeth, and oral structures?

Second domain:(four questions about Child's functions)

2. Does your child have difficulty in drinking hot or cold drinks?

3. Does your child have difficulty in eating some foods?

4. Does your child have difficulty in pronouncing words?

5. Does your child have missed preschool or school days? 
Third domain: (Two questions about Child's psychology):

6. Does your child have sleeping problems?

7. Is your child usually irritable or frustrated?

Fourth domain (Two questions about social interaction of the child):

8. Does your child avoid smiling or laughing with other children?

9. Does your child avoid talking with other children?

\section{Family's two domains:}

\section{First domain (Two questions about family distress):}

10. Have you or any other member of the family been upset because of your Child's dental problem?

11. Did you Feel guilty about your child?

Second domain (Two questions about family function):

12. How often have you or another family member, taken time off work because of your child's dental problems or treatment appointments ?

13. How often your Child's dental problems or treatments had a financial impact on your family? ${ }^{(23,26)}$

So this questionnaire involved 13 questions which are suitable for preschool children ${ }^{(24)}$. Each question asked about an oral health related problem was given a score from 0 to 5 using Likert scale $(29,30,31)$ where :

$$
\begin{aligned}
& 0=\text { never } \\
& 1=\text { hardly ever } \\
& 2=\text { occasionally } \\
& 3=\text { often } \\
& 4=\text { very often } \\
& 5=\text { don't know }
\end{aligned}
$$

All questions have been translated from English language to Classical Arabic using English-Arabic dictionary in order to be readable and understandable for the parents.
For calculation of ECOHIS all the scores of 13 questions were added to give the total score, where a higher score means a higher impact on the child and his family and worse quality of life ${ }^{(12)}$.

Parents received this questionnaire on the day of the GA session to be completed about the child's oral health conditions and well-being over the past 3 months. Then the same questionnaire was used and completed once again in the first follow up visit one month later.

\section{The statistical analysis:}

Data were statistically described in terms of mean standard deviation ( SD), or frequencies (number of cases) and percentages when appropriate. Comparison of numerical variables between the study groups was done using Student t test for independent samples. For comparing categorical data, Chi square test was performed. Exact test was used instead when the expected frequency is less than 5. Correlation between various variables was done using Pearson moment correlation equation for linear relation in normally distributed variables and Spearman rank correlation equation for nonnormal variables/nonlinear monotonic relation. $\mathrm{p}$ values less than 0.05 was considered statistically significant.

All statistical calculations were done using computer program SPSS (Statistical Package for the Social Science; SPSS Inc., Chicago, IL, USA) release 15 for Microsoft Windows (2006).

All statistical analysis was conducted using computer program SPSS (Statistical Package for the Social Science; SPSS Inc., Chicago, IL, USA) release 15 for Microsoft Windows (2006).

\section{RESULTS}

A total of 180 preschool children (of both sexes) participated in this study and received dental treatment under GA during July, August and September 2015 in the Pediatric Dentistry Department Faculty of Oral and Dental Medicine, Cairo University. Parents of all participants 
answered questionnaire on the day of GA session as well as one month later during the first follow up visit. All participants attended in the follow up and no missing data were recorded.

Table (1) revealed that there was no impact of age or sex on the total ECOHIS except for the family function domain where statistically significant difference was higher for male than for females $(3.16 \pm 2.2$ in male vs. $2.4 \pm 1.9$ in females at $\mathrm{p}$ value 0.018 ). Moreover the same table shows a great impact of parent educational level on the family function and family impact scale and total ECHOIS (3.97 vs. $1.27,8.08$ vs. 5.65 and 18.94 vs. 15.6 respectively) in low and middle vs. high parent educational level.

Table (2) shows comparison between the total ECOHIS and all ECOHIS domains before and after dental treatment under GA. Table (2) showed that the total ECOHIS and all ECOHIS domains were significantly and dramatically decreased except for the domain of child psychology which was insignificantly decreased after dental treatment under general anesthesia.

Table (3) showed the most and the least reported items among the 13 questions of the questionnaire used in this study. This table revealed that pain was the most reported item for the child before GA treatment ( $81.7 \%$ ) followed by difficulty in eating ( $66.7 \%)$ and in drinking hot or cold drinks ( 61.7\%) then the other domains. While the least reported items for the child were avoidance of smiling and speaking (5\% each). However for the family, the most reported items were the sense of guilt (65\%) towards the child followed by being upset $(62.8 \%)$, then the financial burden $(58.3 \%)$.While the least reported item for the family was taking days off work $(36 \%)$.

TABLE (1) Pre-treatment_ECHOIS scores among different sexes, age groups and levels of parental education.

\begin{tabular}{|c|c|c|c|c|c|c|c|c|c|}
\hline \multirow{2}{*}{ Domain } & \multicolumn{3}{|c|}{ Sex } & \multicolumn{3}{|c|}{ Age Group } & \multicolumn{3}{|c|}{ Parental Education } \\
\hline & Male & Female & P-Value & $<4 \mathrm{yrs}$ & $4-<6$ yrs & P-Value & High & Low\& Medium & P-Value \\
\hline \multirow{2}{*}{ Pain } & 2.55 & 2.37 & \multirow{2}{*}{0.283} & 2.37 & 2.58 & \multirow{2}{*}{0.196} & 2.35 & 2.57 & \multirow{2}{*}{0.178} \\
\hline & \pm 1.1 & \pm 1.1 & & \pm 1.111 & \pm 1.087 & & \pm 1.191 & \pm 1.027 & \\
\hline \multirow{2}{*}{ Function } & 4.65 & 5.03 & \multirow{2}{*}{0.468} & 4.59 & 5.01 & \multirow{2}{*}{0.41} & 4.35 & 5.13 & \multirow{2}{*}{0.131} \\
\hline & \pm 3.219 & \pm 3.745 & & \pm 3.329 & \pm 3.552 & & \pm 2.607 & \pm 3.913 & \\
\hline \multirow{2}{*}{ Psychology } & 2.78 & 3.05 & \multirow{2}{*}{0.47} & 3.02 & 2.77 & \multirow{2}{*}{0.504} & 3 & 2.82 & \multirow{2}{*}{0.631} \\
\hline & \pm 2.461 & \pm 2.525 & & \pm 2.510 & \pm 2.468 & & \pm 2.477 & \pm 2.499 & \\
\hline \multirow{2}{*}{$\begin{array}{c}\text { Social } \\
\text { interaction }\end{array}$} & 0.37 & 0.2 & \multirow{2}{*}{0.248} & 0.31 & 0.29 & \multirow{2}{*}{0.891} & 0.24 & 0.34 & \multirow{2}{*}{0.489} \\
\hline & \pm 1.049 & \pm 0.870 & & \pm 1.004 & \pm 0.962 & & \pm 0.913 & \pm 1.027 & \\
\hline \multirow{2}{*}{$\begin{array}{c}\text { Child's impact } \\
\text { scale }\end{array}$} & 10.35 & 10.65 & \multirow{2}{*}{0.688} & 10.29 & 10.66 & \multirow{2}{*}{0.618} & 9.93 & 10.87 & \multirow{2}{*}{0.212} \\
\hline & \pm 4.818 & \pm 5.137 & & \pm 4.783 & \pm 5.104 & & \pm 3.319 & \pm 5.545 & \\
\hline \multirow{2}{*}{ Family distress } & 4.34 & 4.05 & \multirow{2}{*}{0.456} & 4.15 & 4.29 & \multirow{2}{*}{0.713} & 4.4 & 4.1 & \multirow{2}{*}{0.468} \\
\hline & \pm 2.5 & \pm 0.27 & & \pm 2.5 & \pm 2.6 & & \pm 2.4 & \pm 2.7 & \\
\hline \multirow{2}{*}{ Family function } & 3.16 & 2.4 & 0.018 & 2.84 & 2.85 & \multirow{2}{*}{0.974} & 1.27 & 3.97 & 0 \\
\hline & \pm 2.2 & \pm 1.9 & $*$ & \pm 2.1 & \pm 2.2 & & \pm 1.7 & \pm 1.7 & $* * *$ \\
\hline \multirow{2}{*}{$\begin{array}{l}\text { Family impact } \\
\text { scale }\end{array}$} & 7.5 & 6.45 & \multirow{2}{*}{0.068} & 6.99 & 7.14 & \multirow{2}{*}{0.791} & 5.65 & 8.08 & 0 \\
\hline & \pm 3.908 & \pm 3.60 & & \pm 3.646 & \pm 3.977 & & \pm 3.319 & \pm 3.832 & $* *$ \\
\hline \multirow{2}{*}{ Total ECHOIS } & 17.86 & 17.11 & 0403 & 17.3 & 17.8 & 0621 & 15.6 & 18.94 & 0.002 \\
\hline & \pm 7.3 & \pm 7.1 & 0.40 & \pm 6.6 & \pm 7.8 & 0.001 & \pm 6.1 & \pm 7.6 & $* * *$ \\
\hline
\end{tabular}

* Statistically significant difference at p-value $\leq 0.05$ 
From the same table we can observe that the most reported items for the child after GA treatment was difficulty in eating (14.4\%) followed by pain $(9.4 \%)$. While for the family the most reported item was the financial burden (7.2\%).

Table (4) showed the correlation between the order of the child among siblings $\left(2^{\text {nd }}\right.$, or $\left.3^{\text {rd }}\right)$ as well as the number of children in the family (more than 2 children) and the ECOHIS domains before and after GA treatment. From this table we can observe that insignificant very weak negative correlation was found with increasing the order of the child among siblings $(r=-0.035)$.

TABLE (2): Comparison between ECOHIS before and after dental treatment under general anesthesia:

\begin{tabular}{|l|l|l|l|}
\hline Domain & Before mean $\pm \mathrm{SD}$ & After mean $\pm \mathrm{SD}$ & P-Value \\
\hline Pain & $2.48 \pm 1.101$ & $0.26 \pm 0.778$ & $0.000^{*}$ \\
\hline Function & $4.81 \pm 3.443$ & $0.41 \pm 0.955$ & $0.000^{*}$ \\
\hline Psychology & $2.89 \pm 2.485$ & $0.08 \pm 0.373$ & 0.603 \\
\hline Social interaction & $0.30 \pm 0.980$ & $0.000 \pm 000$ & Not computed \\
\hline Child Impact scale & $10.48 \pm 4.942$ & $0.74 \pm 1.874$ & $0.000^{*}$ \\
\hline Family distress & $4.23 \pm 2.6$ & $.65 \pm 1.5$ & $0.000^{*}$ \\
\hline Family Function & $3.12 \pm 2.4$ & $.86 \pm 1.7$ & $0.000^{*}$ \\
\hline Family impact scale & $7.07 \pm 3.811$ & $0.42 \pm 1.637$ & $0.006^{*}$ \\
\hline Total ECOHIS & $17.54 \pm 7.220$ & $1.16 \pm 3.249$ & $0.000^{*}$ \\
\hline
\end{tabular}

*Statistically significant difference at p-value $\leq 0.05$

TABLE (3): Frequency of the least and most reported items before and after G.A. treatment among 13 questions:

\begin{tabular}{|c|c|c|c|c|c|c|c|c|c|}
\hline \multirow{3}{*}{ Items $13 \mathrm{Q}$. } & \multicolumn{4}{|c|}{ Least Reported never/hardly ever } & \multicolumn{4}{|c|}{$\begin{array}{l}\text { Most Reported occasionally } \\
\text { / often/ very often }\end{array}$} & \multirow{3}{*}{ P-Value } \\
\hline & \multicolumn{2}{|c|}{ Before } & \multicolumn{2}{|c|}{ After } & \multicolumn{2}{|c|}{ Before } & \multicolumn{2}{|c|}{ After } & \\
\hline & no. & $\%$ & no. & $\%$ & no. & $\%$ & no. & $\%$ & \\
\hline 1-Pain & 33 & 18.3 & 163 & 90.6 & 147 & 81.7 & 17 & 9.4 & $0.000 *$ \\
\hline 2-Difficulty in drinking hot/cold & 87 & 48.3 & 176 & 97.8 & 93 & 61.7 & 4 & 2.2 & $0.000^{*}$ \\
\hline 3-Difficulty in eating & 60 & 33.3 & 154 & 85.6 & 120 & 66.7 & 26 & 14.4 & $0.000 *$ \\
\hline 4-Difficulty in pronouncing words & 157 & 87.2 & 180 & $100 \%$ & 23 & 12.8 & 0 & $0 \%$ & $0.000^{*}$ \\
\hline 5-Missing preschool days & 123 & 68.3 & 180 & $100 \%$ & 57 & 31.7 & 0 & $0 \%$ & $0.000^{*}$ \\
\hline 6-Sleeping troubles & 86 & 47.8 & 174 & 96.7 & 94 & 52.2 & 6 & 3.3 & $0.000 *$ \\
\hline 7- frustrated & 94 & 52.2 & 180 & $100 \%$ & 86 & 47.8 & 0 & $0 \%$ & $0.000 *$ \\
\hline 8- Avoid smiling & 171 & 95 & 180 & $100 \%$ & 9 & 5 & 0 & $0 \%$ & $0.000^{*}$ \\
\hline 9-Avoid talking & 171 & 95 & 180 & $100 \%$ & 9 & 5 & 0 & $0 \%$ & $0.000 *$ \\
\hline 10-Parents feeling upset & 67 & 37.2 & 173 & 96.1 & 113 & 62.8 & 7 & 3.9 & $0.000^{*}$ \\
\hline 11-Parents feeling guilty & 63 & 35 & 176 & 97.8 & 117 & 65 & 4 & 2.2 & $0.000 *$ \\
\hline 12-Parents take days off from work & 115 & 63.9 & 179 & 99.4 & 65 & 36.1 & 1 & 0.6 & $0.000^{*}$ \\
\hline 13-Financial burden on family & 75 & 41.7 & 167 & 92.8 & 105 & 58.3 & 13 & 7.2 & $0.000 *$ \\
\hline
\end{tabular}

*Statistically significant difference at p-value $\leq 0.05$ 
TABLE (4) correlations ( $r$ ) between ECHIO domain and order of the child among siblings as well as the no. of children in family:

\begin{tabular}{|c|c|c|c|c|}
\hline \multirow{2}{*}{ Domains } & \multicolumn{2}{|c|}{ Child's Order $\left(2^{\text {nd }}-3^{\text {rd }}\right)$} & \multicolumn{2}{|c|}{ Child's no. in the family ( $>$ than 2 ) } \\
\hline & Correlation (r) & P-value & Correlation (r) & P-value \\
\hline 1) Pain (Before) & -0.065 & 0.385 & -0.018 & 0.815 \\
\hline Pain (After) & 0.011 & 0.879 & 0.113 & 0.131 \\
\hline 2) Function (Before) & -0.096 & 0.2 & 0.047 & 0.527 \\
\hline Function (After) & -0.003 & 0.967 & 0.074 & 0.324 \\
\hline 3) Psychology (Before) & 0.016 & 0.843 & -0.016 & 0.831 \\
\hline Psychology (After) & $0.40 *$ & 0.594 & 0.06 & 0.42 \\
\hline 4) Social interactions (Before) & 0.057 & 0.444 & 0.068 & 0.362 \\
\hline Social interaction (After) & Not computed & Not computed & Not computed & Not computed \\
\hline 5) Child's impact (Before) & -0.042 & 0.574 & 0.049 & 0.511 \\
\hline Child's impact (After) & 0.011 & 0.882 & 0.081 & 0.277 \\
\hline 6) Family impact (Before) & 0.003 & 0.965 & 0.025 & 0.743 \\
\hline Family impact (After) & 0.045 & 0.552 & 0.099 & 0.187 \\
\hline 7) Total ECOHIS (Before) & -0.035 & 0.636 & 0.025 & 0.737 \\
\hline Total ECOHIS (After) & 0.036 & 0.636 & 0.102 & 0.172 \\
\hline
\end{tabular}

\section{DISCUSSION}

The current study was conducted on a group of Egyptian preschool children (180 cases) with an age ranged between $2 \leq 6$ years in order to assess the OHRQOL among those children and their families before and after dental treatment under general anesthesia.

All of them were referred to the general anesthesia unit of Pediatric Dentistry Department, Faculty of Oral and Dental Medicine, Cairo University which is considered the biggest and the most important educational dental hospital in Egypt offering dental treatment under general anesthesia for preschool, school children and those with special health care needs.

This study was conducted during July, August and September 2015 as this is the peak of patient's flow to the hospital among all months of the year.
In the current study the authors used ECOHIS questionnaire to evaluate the OHRQOL of children and their families before and after general anesthesia treatment. ECOHIS questionnaire was especially designed for preschool children ${ }^{(24)}$, it is a short and concise form containing 13 questions only.

The ECOHIS 13 questions were answered by the parents two times. The first was at the day of general anesthesia while the second was one month later in the first follow up visit.

Among the points of strength in this study that:

First: we have no drop out cases and all of them attended in the follow up visit to take pieces of advice about their children's oral health.

Second: no answers with don't know were recorded in the questionnaire neither on the day of general anesthesia session nor in the follow up visit which could be explained on the basis that, 
all questions were translated in an easy way for the parents to read, understand and answer. Both parents answered the questionnaire as usually the child was brought to the general anesthesia unit with his/her parents and sometimes grandfather or grandmother.

The results of this study showed that sex and age had no impact on the total ECOHIS scores and accordingly on the quality of life except for the family function domain which was significantly affected with boys than girls (table 1) this result could be attributed in our opinion to over love and over affection for boys than girls in some Arab countries due to cultural beliefs and traditions.

Results also showed that, with higher parental educational level the family function domain, family impact scale and total ECOHIS scores were significantly lower which means better quality of life. This results goes in agreement with ${ }^{(13,32)}$ who reported that higher level of maternal education is usually accompanied by better quality of life for their children and for the family in general.

By comparing the ECOHIS before general anesthesia treatment and one month after in the follow up visit the results showed great improvement in all child's impact and family impact domains as well as in the total ECOHIS with statistically significant difference in all domains which means great improvement in the quality of life. Table (2) shows the mean ECOHIS score was 17.54 before and 1.16 after general anesthesia treatment with a degree of reduction 16.38 . The same finding was reported by ${ }^{(16,27,33)}$ Who attributed it to the great effect of ECC on the quality of life before treatment and to the great improvement after treatment.

The only domain which was improved after general anesthesia treatment but with no statistical difference was the child psychology 2.89 and 0.08 respectively with a degree of reduction 2.81 . These results could be attributed to multiple teeth extraction during treatment or multiple stainless steel crown restorations with its metallic appearance which means that even after general anesthesia treatment the effect of ECC is still present. This result was strongly supported by ${ }^{(23)}$. Meanwhile the social interaction domain (smiling, talking and sharing social activities) were greatly improved and children became more attentive to school ${ }^{(21,34)}$. However ${ }^{(35,36)}$ reported another opinion regarding social interaction and wellbeing that dental treatment under general anesthesia can offer only symptomatic relief such as pain ,eating, drinking and dental functions in general rather than long term treatment in the form of social interaction and psychological support .

Regarding the most reported domains before general anesthesia treatment, the results showed that pain $(81.7 \%)$ was the highest reported followed by difficulty in eating (66.7\%), then difficulty in drinking (61.7\%) table (3). This means that those domains had a great impact on the quality of life of the child, this result goes in accordance with ${ }^{(32,34)}$ who explained that these findings may affect greatly sleep, school attendance and general health of the child

While in the family impact section, the domain of family distress (feeling guilty and being upset) was the highest reported as well as the financial burden on the family $(65 \%, 62 \%$ and $58.3 \%$ respectively), this result was strongly supported by ${ }^{(32,33,34)}$. While after general anesthesia treatment, the most reported was difficulty in eating for the child which could be explained on the basis that the child used to avoid eating on decayed teeth due to pain or may be due to multiple teeth extraction. On the other hand the financial burden for the family was the most reported domain after general anesthesia treatment as the parents share in the treatment fees of their child in the general anesthesia unit so the treatment here is paid although it's non profitable unit.

By correlating the child's order in the family the total ECOHI and quality of life the results showed a negative but insignificant correlation was found with increasing the child's order $\left(2^{\text {nd }} / 3^{\text {rd }}\right.$ or youngest 
child) table (4). This result goes in agreement with $^{(37,38)}$ who explained this finding on the basis that family income, financial resources, and even the parents affection and attention are usually distributed among all family members and all siblings so with increasing the number of children in the family as well as the order of the child among siblings poor ECOHQL can be found.

\section{CONCLUSION}

ECC has a great impact on the quality of life of both children and their families .High scores of ECOHIS were recorded before DGA which means poor quality of life, while these scores were dramatically decreased after DGA with a significant improvement in the quality of life and strong appreciation from the parents.

\section{REFERENCES}

1. World Health Organization (WHO): Oral Health Surveys. Basic Method, 1997.

2. Savage MF, Lee JY, Cotch JB and Vann WF: Early Preventive Dental Visits: Effect on subsequent utilization and costs. Pediatrics,(114):418-423 2004.

3. Martins-Junior PA, Vieira-Andrade RG, Correa-Faria P, Oliviera-Ferreira F, Marques LS, and Ramos- J Orge ML: Impact of early childhood caries on the oral health related quality of life of preschool children and their parents. Caries Res, 47: 211-218, 2013.

4. Nuttall NM, Stelee JG, Chadwick B, Morris AJ and Hill $\mathrm{K}$ : The reported impact of oral condition on children in the United Kingdom, British Dental Jurnal.200 (10):551$556,2006$.

5. Casamassimo P, Thikkurissy S, Edelstein BL and Malorini E: Beyond the DMFT: the human and economic costs of early childhood caries. JADA ,(140):650-657, 2009.

6. Blumenshine SL, Vann WF, Gizlice Z and Lee JY: Children School Performance: Impact of General and Oral Health.J of Public Health Dentistry,68(2):82-87, 2008.

7. Thomas $\mathrm{CW}$ and Primosch RE: Changes in Incremental Weight and Well-Being of Children with Rampant Caries Following Complete Dental Rehabilitation. Pediatr. Dent., 24(2): 109-113, 2002.
8. Congiu G, Campus G and luglie PF: Early Childhood Caries (ECC) Prevalence and background factors, oral Health Prev. Dent, 12 (1): 71-76, 2014.

9. Hakan c, Colak T, Dulgergil and Mehmet MH: Early Childhood Caries Update; A review of causes diagnosis and treatment, J of Nat SCI Biol Med, Jan- Jun, 4 (1): 29-38, 2013

10. Razmiene J, Vanagas V, Bendoraitiene E, and Vysniauskaite A.: The relation between oral hygiene skills and prevalence of dental caries among 4-6 years old children. Stomatologija. Baltic. Dent. Maxillofac. J; (13): 62-67, 2001.

11. Slabsinskiene E, Milciuviene S, Narbutaite J, Vasiliauskiene I, el al; Severe early childhood caries and behavioral risk factors among 3- years old children in Lithuania. Medicina (Kaunas)46: 135-141, 2010.

12. Jankauskiene B, Narbutaite J, Kubilius R and Gleiznys A: Adaptation and validation of the early childhood oral health impact scale in Lithuania Stomatologija, Baltic Dental and Maxillofacial J. (14) 108-113, 2012.

13. Jankauskiene B, Vertanen J, Kubilius R, and Narbutaite $\mathrm{J}$.:Oral health related quality of life after dental general anesthesia treatment Among children: A follow up study. Open access article and can be found online at: http:/www. biomedcentral.com/ 1427-6831/14/81, 2014.

14. Andruskeviciene V, Milciuviene S, Bendoraitiene E, Saldunaite $\mathrm{K}$, and others: Oral health status and effectiveness of caries prevention program in kindergartens in Kaunas city (Lithuania) Oral Health Prev Dent,(6): 343-348, 2008.

15. Portwood H, A : Early childhood caries under General Anesthesia: A burden analysis ,Master thesis of science in the graduate school of Ohio State university , 2010 Available on line on https:/etd.ohiolink.edu

16. Malden P. E, Thomas W .M, Jokovic A, and Locker D.: Changes in parent- assessed oral health related quality of life among young children following dental treatment under general anesthesia. Community Dent Oral Epidemiol.,( 36 ): 108-117, 2008.

17. Eaton JJ,c Mc Tigue DJ, Fields HW, and Beck FM.: Attitudes of contemporary parents towards behavior management techniques used in pediatric dentistry. J Pediatr. Dent. 27 (2): 107-113, 2005.

18. Jankauskiene B, Viranen JI, Kubilius R, and Narbutaite J: Oral health related quality of life after dental general anesthesia treatment among children: a follow up study. BMC Oral Health 2014, the electronic version can be found online at: http:/www.biomedcentral.com/1472-6831/14/81 
19. Amin MS, Harrison RL and Weinstein P. A qualitative look at parents' experience of their child's dental general anesthesia. Int J of Pediatr Dent. 16: 309-319, 2006.

20. Baens-Ferrer C, Roseman MM, Dumas HM and Haley SM. Oarental perceptions of oral health- related quality of life for children with special needs: Impact of oral rehabilitation under general anesthesia. Pediatr Dent.; 27(2):137-142, 2005.

21. Andreson HK, Drummond BK and Tomson WM. Changes in aspects of children's oral health related quality of life following dental treatment under general anesthesia. Int J of Pediatr Dent. 14: 317-25, 2004.

22. Filstrup SL, Briskie D, da Fonseka M, Lawrence L, Wandera A, and Inglehart MR: Early childhood caries and quality of life: child and parents, prespectives. Paediatr Dent, 25: 431-440, 2003.

23. Jokovic A, Locker D, Stephens M, Kenny D, Tompson B, and Guyatt G. Measuring parental perceptions of child oral health-related quality of life. J Public Health Dent, 63: 67-72,2003.

24. Pahel BT, Rozier RG, Slade GD: Parental perceptions of children's oral health: the Early childhood oral health impact scale (ECOHIS) Health Qual Life Outcomes ,5: 6, 2007.

25. Thomson WM, Gaynor WN, Malden PE, Foster page LA: Short-form version of the parental-caregivers perception questionnaire (P-CPQ) and the family impact scale (FIS). Community Dent oral Epidemiol, 41: 441-450, 2013.

26. Thomson WM, Malden PE: Assessing change in the family impact of caries in young children after treatment under general anesthesia. Acta Odontol Scand, 69: 257-262, 2011.

27. Lee GH, McGrath C, Yiu CK, and King NM: Sensitivity and responsiveness of the Chinese ECOHIS to dental treatment under general anesthesia. Community Dent Oral Epidemiol, 39: 372-377, 2011.

28. Baghdadi ZD: Effect of dental rehabilitation under general anesthesia on children ,s oral health-related quality of life using proxy short versions of OHRQoL instruments. Scientific World Journal , 2014: 308439

29. Talekar B, Rozier R, Slade G. Parental perceptions of children's oral health: the Early Childhood Oral Health Impact Scale. Health Qual Life Outcomes, 30: 6, 2007.
30. Bordoni N, Beltran Aguilar E, Claravino O, Zambrano O, Villena R. Early Childhood Oral Health Impact Scale (ECOHIS ). Acta Odont Latinoam; 25:270-278, 2012.

31. Peker K, Uysal O, Bermek G. Cross- Cultural adaptation and preliminary validation of Turkish version of the Early Childhood Oral Health Impact Scale among 5-6 year-old children. Health Qual Life Outcomes;9: 2-11, 2011.

32. Baghdadi ZD and Muhajarine N. : Effect of dental rehabilitation under general anesthesia on children,s Oral-HealthRelated Quality of Life: Saudi Arabian Parents, Perspectives . Open Access Article Dentistry Journal 3,1-13 2015 doi: $10.339 / \mathrm{dj} 3010001$

33. Lee GHM, McGrath C, Yiu CKY, King NM: Translation and validation of a Chinese language version of the Early Childhood Oral Health Impact Scale (ECOHIS). Int. J Paediatr Dent ; 19: 399-40, 2009.

34. Lee GHM, McGrath C, Yiu CKY, King NM: A comparison of a genetic and oral health-specific measure in assessing the impact of early childhood caries on quality of life. Community Dent Oral Epidemiol. ;9: 333-338,2010.

35. Souza MC, Harrison M and Marsh man ZOE: Oral health related quality of life following dental treatment under general anesthesia for early childhood caries- a UK based study. International journal of pediatric dentistry 2016 (open access article)

36. Marayza Alves Clementino, Monalisa Cesarino Gones, Tassia Cristina de, Almeida Pinto-Sarmento, Carolina Castro Martins, Ana Flavia Granville-Garcia, and Saul Martins Paiva: Perceived impact of dental pain on the quality of life of preschool children and their families Research article PLOS ONE DOI:10.1371/journal. Pone.0130602 June 2015.

37. Ridell K, Borgstrom M, Lager E, Magnusson G, BrogardhRoth S and Matsson L.: Oral health related quality of life in Swedish children before and after dental treatment under general anesthesia. Acta Odontol Scand 73: 1-7, 2015.

38. Hearton TB, Forste R, Hoffmann JP, Flake D: Crossnational variation in family influences on child health. Soc Sci. Med. 60: 97-108 2005 PMID:15482 